\title{
Pharmacophore and receptor models for neurokinin receptors
}

\author{
Anders Poulsen ${ }^{\mathrm{a}, \mathrm{b}}$, Berith Bjørnholm ${ }^{\mathrm{b}}$, Klaus Gundertofte ${ }^{\mathrm{b}}$, Irina D. Pogozheva ${ }^{\mathrm{c}}$ \& Tommy \\ Liljefors ${ }^{\mathrm{a}, *}$ \\ ${ }^{\mathrm{a}}$ Department of Medicinal Chemistry, The Danish University of Pharmaceutical Sciences, 2 Universitetsparken, \\ DK-2100 Copenhagen, Denmark; ${ }^{\mathrm{b}} \mathrm{H}$. Lundbeck A/S, 9 Ottiliavej, DK-2500 Copenhagen-Valby, Denmark; \\ ${ }^{\mathrm{c}}$ College of Pharmacy, University of Michigan, Ann Arbor, MI 48109, USA
}

Received 7 January 2003; accepted in revised form 14 November 2003

Key words: bioactive conformation, conformational analysis, GPCR, MMFF force field, neurokinin, neurokinin A, neurokinin B, NK1 receptor, NK2 receptor, NK3 receptor, pharmacophore model, 7TM receptor model, substance $\mathrm{P}$, subtype selectivity, tachykinin

\section{Summary}

Three neurokinin (NK) antagonist pharmacophore models (Models 1-3) accounting for hydrogen bonding groups in the 'head' and 'tail' of NK receptor ligands have been developed by use of a new procedure for treatment of hydrogen bonds during superimposition. Instead of modelling the hydrogen bond acceptor vector in the strict direction of the lone pair, an angle is allowed between the hydrogen bond acceptor direction and the ideal lone pair direction. This approach adds flexibility to hydrogen bond directions and produces more realistic RMS values. By using this approach, two novel pharmacophore models were derived (Models 2 and 3) and a hydrogen bond acceptor was added to a previously published NK2 pharmacophore model [Poulsen et al., J. Comput.-Aided Mol. Design, 16 (2002) 273] (Model 1). Model 2 as well as Model 3 are described by seven pharmacophore elements: three hydrophobic groups, three hydrogen bond acceptors and a hydrogen bond donor. Model 1 contains the same hydrophobic groups and hydrogen bond donor as Models 2 and 3, but only one hydrogen bond acceptor. The hydrogen bond acceptors and donor are represented as vectors. Two of the hydrophobic groups are always aromatic rings whereas the other hydrophobic group can be either aromatic or aliphatic. In Model 1 the antagonists bind in an extended conformation with two aromatic rings in a parallel displaced and tilted conformation. Model 2 has the same two aromatic rings in a parallel displaced conformation whereas Model 3 has the rings in an edge to face conformation. The pharmacophore models were evaluated using both a structure (NK receptor homology models) and a ligand based approach. By use of exhaustive conformational analysis (MMFFs force field and the GB/SA hydration model) and least-squares molecular superimposition studies, 21 non-peptide antagonists from several structurally diverse classes were fitted to the pharmacophore models. More antagonists could be fitted to Model 2 with a low RMS and a low conformational energy penalty than to Models 1 and 3. Pharmacophore Model 2 was also able to explain the NK1, NK2 and NK3 subtype selectivity of the compounds fitted to the model. Three NK 7TM receptor models were constructed, one for each receptor subtype. The location of the antagonist binding site in the three NK receptor models is identical. Compounds fitted to pharmacophore Model 2 could be docked into the NK1, NK2 and NK3 receptor models after adjustment of the conformation of the flexible linker connecting the head and tail. Models 1 and 3 are not compatible with the receptor models.

\section{Introduction}

The neurokinin receptors (NKRs) are peptides composed of 350 to 500 amino acids. They belong to the superfamily of G-protein coupled receptors (GPCRs) [1]. Three NKR subtypes, NK1, NK2 and NK3, have

\footnotetext{
${ }^{*}$ To whom correspondence should be addressed. E-mail: tl@dfuni.dk
} 
been identified by molecular cloning and sequence analysis. They are characterised by their endogenous ligands. NK1 has highest affinity for substance P, NK2 has highest affinity for NKA and NK3 has highest affinity for NKB [1]. Most of the published NK antagonists contain at least two ring systems connected by a linker holding a hydrogen bond acceptor. We define this part of the NK antagonists as the head fragment, and the rest is defined as the tail (Figure 1). The tail of the majority of NK antagonists contains a basic nitrogen, a hydrophobic group and a hydrogen bond acceptor. We have previously reported an NK2 pharmacophore model (Figure 2) [2]. In this model, the antagonists bind in an extended conformation with two aromatic groups in a parallel displaced and tilted conformation [3] (A and B in Figure 2). The model consists of an additional hydrophobic group and a hydrogen bond donor represented as a vector $(\mathrm{C}$ and $\mathrm{D}$ in Figure 2, respectively). Most of the studied NK antagonists have a piperidine ring in the tail. The most probable orientation of pharmacophore element $\mathrm{C}$ is equatorial relative to the piperidine ring. This model agrees with NK1/NK2 and NK2/NK3 receptor model studies [4, 5]. However, a serious drawback of the model which was made clear to us through an extended search for and analysis of NK receptor antagonists is that it does not account for the importance of hydrogen bond accepting groups in the head and tail of NK antagonists. The importance of such groups is, for example, demonstrated by compounds 2 and $\mathbf{3 4}$. In 34, the amide group in the tail of $\mathbf{2}$ has been removed and the compound displays a more than 200-fold decrease in affinity. All attempts to add hydrogen bond acceptor pharmacophore elements to the head and tail part of the ligands proved futile if the positions and orientations of the pharmacophore elements were kept the same as in the previously reported model. Thus, in order to investigate if such hydrogen bonding can be accounted for, the conformational properties of the ligands have been re-investigated, searching for alternative positions and orientations of the pharmacophore elements.

To add some flexibility to hydrogen bond directions in the molecular superimpositions, we have in the present study used a procedure in which an angle is allowed between the hydrogen bond acceptor direction and the strict lone pair direction (Figure 3). This procedure results in more realistic RMS values and more pharmacophore elements can be incorporated in the models. The procedure is similar to that used in programs for 3D database searching where the end-

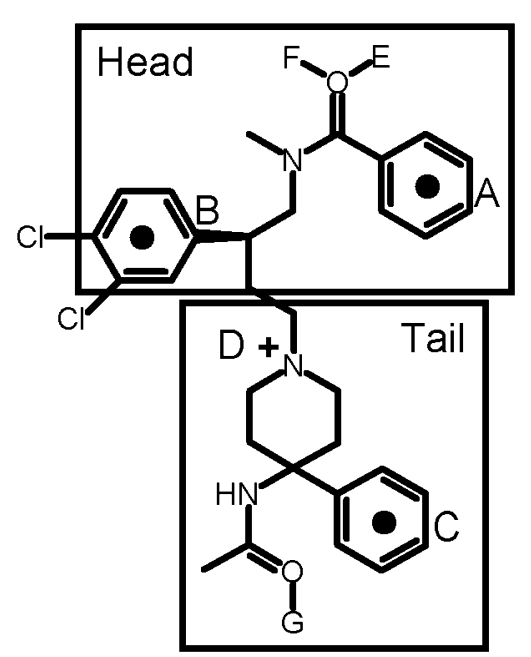

Figure 1. Definition of fragments with compound $\mathbf{2}$ as an example. Centroids, lone pairs and ' + ' mark the selected pharmacophore elements $\mathrm{A}-\mathrm{G}$.

point of the hydrogen bond vector is allowed to reside inside a sphere. This is equivalent to allow for both an interval on the angle between the hydrogen bond and the lone pair direction and an interval on the length of the vector.

By using this procedure for treatment of hydrogen bonds during superimposition we have now developed three alternative pharmacophore models that incorporate these hydrogen bond acceptors. The performance of these alternative models has been assessed by fitting 21 non-peptide antagonists to the model and additionally by docking the ligands to homology models of the subtypes of the NK receptor, guided by results from mutational studies.

As is the case for most GPCRs, NKRs have not yet been crystallised, so no experimental structures are available. However, the X-ray structure of the GPCR bovine rhodopsin has recently been published [6] and the NKRs have sufficient sequence homology to bovine rhodopsin that an alignment can be made. The GPCRs contain seven transmembrane $\alpha$ helices (7TM) of approximately 25 residues length. The helices are connected by intra- and extracellular loops. The N-terminal is located on the extracellular side whereas the C-terminal extends into the cytoplasm. The loop regions and the $\mathrm{N}$ - and C-termini are surrounded by an aqueous environment and consist primary of hydrophilic amino acids. The 7TM region is in a lipid environment and consists mainly of hydrophobic amino acids. Some experimental work has been published from which structural information of 
the NKR has been obtained. Elling et al. [7, 8] have performed extensive mutagenesis work to identify zinc ion binding sites in the NK1R. Donnelly et al. [9] have made a Asp79Asn + Asn303Asp NK2R double mutant and they conclude that there is a direct interaction between the side chains of the two residues. That places TM2 and TM7 in contact, and the relative orientation of the two helices can be deduced.

Several receptor modelling studies of the NK1R [4, 10-13], the NK2R [4, 5, 14, 15] and the NK3R [5] have been published. These models are based on the bacteriorhodopsin cryo electron microscopy structure by Henderson et al. [16] or the rhodopsin structure by Baldwin et al. [17]. Bacteriorhodopsin is a proton pump, not a GPCR, and the sequence identity with any known GPCR is too low for sequence based alignment. Furthermore, the resolution of these structures is too low to provide the atomic coordinates directly. Thus, bacteriorhodopsin is not an ideal template for modelling GPCRs. Rhodopsin is a true GPCR. Baldwin's rhodopsin model is based on a cryo microscopy electron density map of frog rhodopsin [18], but the resolution is too low to provide atomic coordinates directly. Using the recently published bovine rhodopsin $\mathrm{X}$-ray structure (PDB file 1F88) [6] as a template is expected to produce better GPCR models. Our NKR models were used to evaluate the pharmacophore models. The conformations of compounds manually docked into the receptor models were compared to the pharmacophore models and the pharmacophore elements were compared to specific interactions observed in the receptor-ligands complex.

The results of the pharmacophore and receptor modelling studies have been used to discuss the molecular determinants for NK receptor subtype selectivity.

\section{Computational methods}

Force fields, conformational analysis and calculation of conformational energies

Conformational space was searched by using the Monte Carlo Multiple Minimum (MCMM) method as implemented in MacroModel 7.1 [19]. Force field calculations were carried out using the MMFF94s force field, the GB/SA hydration model $[20,21]$ and the truncated Newton conjugate gradient algorithm (TNCG) as implemented in MacroModel. The conformational energy penalties were calculated as the difference in internal energy between the putative bioactive conformation and the global energy conformation obtained for aqueous solution (i.e. by subtracting the energy of the global energy minimum in solution excluding the hydration energy from the energy of the putative bioactive conformation) [22]. The solvation energy was calculated by using the GB/SA hydration model $[20,21]$. No compound had a solvation energy that differed markedly from the other compounds. A more detailed description of conformational search, force fields and calculation of the conformational energy penalty is given in [2].

\section{Superimposition studies}

Three hydrophobic rings, one hydrogen bond donor (in most cases the protonated nitrogen atom of an amine) and three hydrogen bond acceptors (two of which are connected to the same carbonyl oxygen) were chosen as pharmacophore elements. For each of the hydrophobic rings, centroids were constructed. The compounds were first fitted to the pharmacophore model using only these centroids as fitting points.

In order to include hydrogen bonding and allow for flexibility in the directions of hydrogen bonds, the following procedure was then employed.

(1) Dummy atoms were placed $2.8 \AA$ from the donor/acceptor atoms in the direction of the putative hydrogen bond interaction vectors defined by the pharmacophore model. Thus, the ideal hydrogen bond directions defined by the directions of lone pairs were not employed.

(2) The compounds were then again fitted to the pharmacophore models now using both the centroids and the dummy atoms described above as fitting points. The RMS values in Tables 1 and 3 were obtained from this second fit. The hydrogen bond donor and acceptor atoms in the molecules were not used in the superimposition.

(3) In order to evaluate the angle of deviation from an ideal hydrogen bond direction, a second hydrogen bonding site point was represented by a dummy atom $2.8 \AA$ from the donor/acceptor atom but now in the direction of the nitrogen-hydrogen bond (for pharmacophore element $D$ ) or the lone pair (for pharmacophore elements $E, F$ and $G$ ).

(4) The angle of deviation between the actual hydrogen bonding direction and the ideal direction was then calculated. This angle, $\varphi$, is defined in Figure 3 where pharmacophore element $F$ in the head fragment of compound 4 is used as an example. 
Least-squares rigid body molecular superimpositions were performed using the MacroModel program. The superimpositions were evaluated in terms of RMS values of the fitting points. An RMS value of $0.6 \AA$ has been used as a soft indicator to determine whether a fit is acceptable or not. The aromatic pharmacophore elements were fitted in a coplanar orientation if energetically possible. The RMS values do not give any measure of this coplanarity since only the centroids are superimposed.

\section{DFT calculations}

The program Jaguar 4.1 [23] was used for B3LYP DFT energy minimisation. The basis set was $6-31 \mathrm{G}^{* *}$ and accuracy level was set to 'accurate'. Otherwise default parameters were used.

\section{Receptor modelling}

The sequence alignment produced for the NKRs was similar to the one obtained from the GPCRDB [24] but slightly modified in the loop regions [25]. NK1R, NK2R and NK3R models were constructed by the iterative distance geometry method of Pogozheva et al. [26]. This approach utilises the program DIANA [27] to construct a protein structure from torsional and distance constraints. The bovine rhodopsin X-ray structure (PDB file 1F88) [6] was used as a template to derive the constraints. The iterations consisted of a cycle with three steps. (1) Examination of the protein structures and the output files from the previous DIANA calculation. Constraint violations and van der Waals clashes are detected. (2) Modifications of the input files with angle and distance constraints. (3) DIANA calculation with the modified constraints. The NK antagonists were manually docked into the receptor models guided by published mutational data $[4$, $15,28]$. The receptor-ligand complex was minimised with all hydrogens using the CHARMm force field [29] with the adopted-basis Newton Raphson method, a dielectric constant of 10 and 50-70 minimisation steps.

\section{Results and discussion}

\section{Construction of the pharmacophore models}

As mentioned in the Introduction, our previously published model [2] does not include hydrogen bond acceptors in the head and tail fragments of NK2 antagonists. Attempts to add a hydrogen bond acceptor pharmacophore element to the head part proved futile with the orientation of the pharmacophore elements as in the previous model. Therefore we searched for new orientations of the pharmacophore elements A and B (Figure 2) for which a hydrogen bond acceptor could be added to the model. Two new orientations were found, leading to pharmacophore Models 2 and 3 . The conformation of the flexible linker connecting the head and tail fragments was retained as in the previous model. This conformation of the linker is the same as in the global energy minimum of compound $\mathbf{2}$. In all three models, pharmacophore elements B, C and $\mathrm{D}$ are in the same positions as in our previous model (Figure 2).

Compounds 1-3 (Figure 4) were used to derive pharmacophore Models 2 and 3, whereas compounds 4-21 were used to evaluate the models. Compounds 1-3 were chosen due to their structurally diverse head fragments. In compound $\mathbf{1}$ the pharmacophore elements A, B, E and F (Figure 1) are connected to a six-membered ring containing an amide functionality, in compound $\mathbf{2}$ the pharmacophore elements are connected by an open chain and in compound 3 an imidazole holds the pharmacophore elements. Compound $\mathbf{3}$ is lacking pharmacophore element F.

Three conformations of each of compounds 1-3 were found for which pharmacophore elements A-D could be superimposed. For the hydrogen bond acceptors in the head fragments, a dummy atom was placed $2.8 \AA$ from the acceptor atom in the direction of the lone pairs, thereby creating a vector (pharmacophore elements $\mathrm{E}$ and F). One mode of superimposition led to the previously published model. The hydrogen bond acceptor-donor vectors (pharmacophore element $\mathrm{E}$ and F) did not superimpose in these conformations. However, for the other two modes of superimposition (Models 2 and 3 ) the hydrogen bond acceptor-donor vector did superimpose. In Models 2 and 3 the positions of the pharmacophore elements are defined as the average coordinate of the pharmacophore elements in the superimposition of compounds $\mathbf{1}-\mathbf{3}$. The positions of pharmacophore elements B, C and D are identical in all three models.

\section{Construction of pharmacophore element $G$}

As evident from Figure 5 and Table 1, the heteroatoms of the tail part of NK2 antagonists are important for the affinity of the compounds. For instance, by comparing 


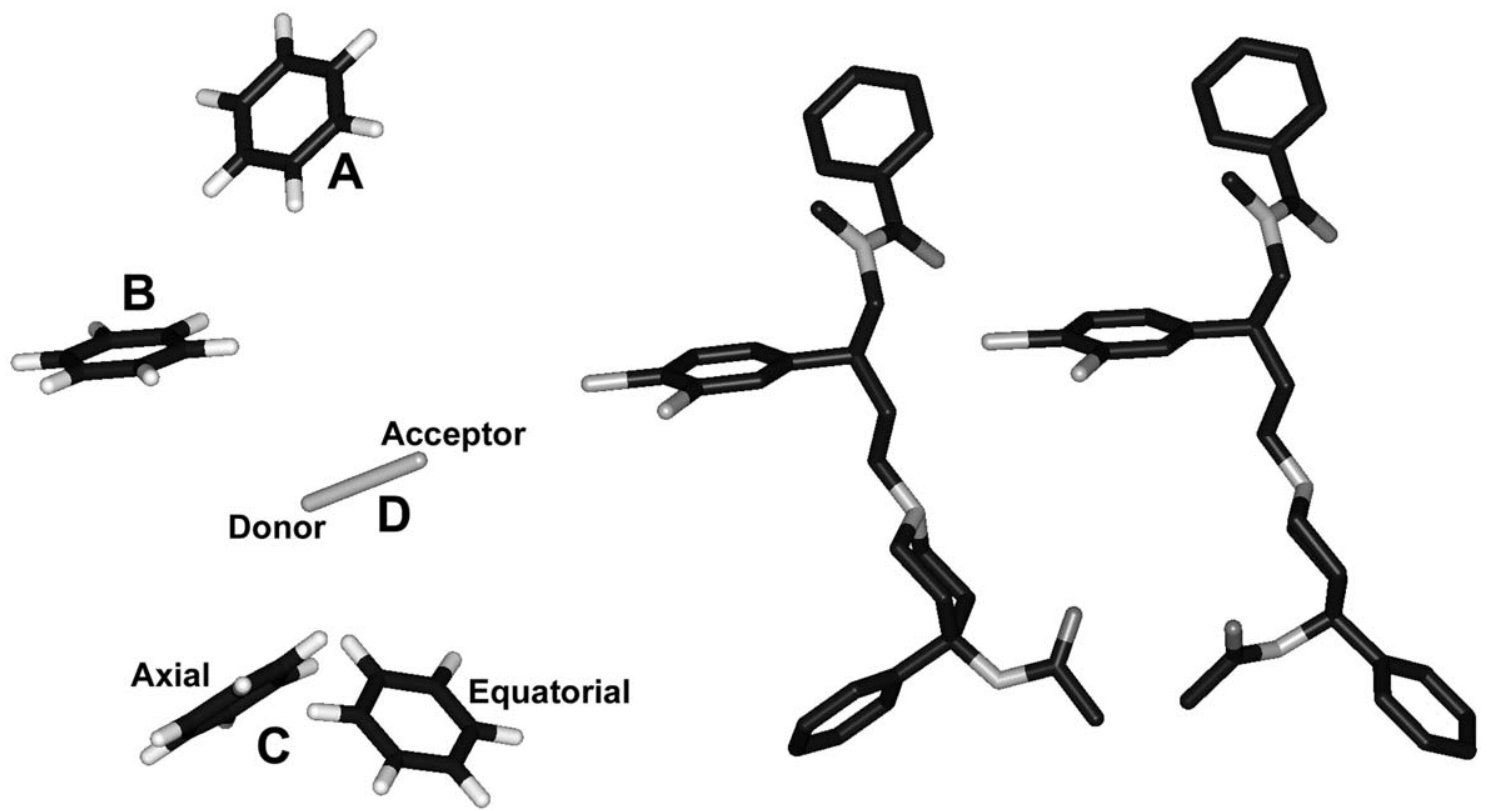

Figure 2. The previously published pharmacophore model. Left: arrangement of pharmacophore elements. Element C can be in an axial or equatorial conformation. We propose that the equatorial conformation is most likely to be the bioactive conformation [2]. Center and right: the putative bioactive conformations of (S)-2 with pharmacophore element $\mathrm{C}$ axial (center) and equatorial (right).

Table 1. Data of compounds fitted to pharmacophore Model 1. HB acceptor angle is the deviation from the ideal hydrogen bond geometry ( $\varphi$ as defined in Figure 3). $\mathrm{IC}_{50}$ is the NK2 affinity of the racemate. $K_{i}$ is the NK2 affinity of the highest affinity enantiomer.

\begin{tabular}{|c|c|c|c|c|c|}
\hline Compound & Reference & $\begin{array}{l}\text { HB acceptor } \\
\text { angle }\left(^{\circ}\right)\end{array}$ & $\begin{array}{l}\mathrm{RMS}^{\mathrm{a}} \\
(\AA)\end{array}$ & $\begin{array}{l}\mathrm{IC}_{50} \\
(\mathrm{nM})\end{array}$ & $\begin{array}{l}\mathrm{K}_{\mathrm{i}} \\
(\mathrm{nM})\end{array}$ \\
\hline 2 & {$[32,39]$} & 32.7 & 0.29 & 4.1 & 0.5 \\
\hline 7 & [39] & 9.3 & 0.11 & 8.9 & \\
\hline 16 & [40] & 25.6 & 0.02 & 7.93 & \\
\hline 22 & [39] & 0 & 0.14 & 12 & \\
\hline 23 & [39] & 29.7 & 0.17 & 13 & \\
\hline 24 & [39] & 98.0 & 0.29 & 4.0 & \\
\hline 25 & [39] & 41.3 & 0.40 & 9.1 & \\
\hline 26 & [41] & 26.0 & 0.25 & & 1.0 \\
\hline 27 & [39] & 22.6 & 0.20 & 84 & \\
\hline 28 & [39] & 24.6 & 0.18 & 30 & \\
\hline 29 & [41] & 47.1 & 0.24 & & 50 \\
\hline 30 & [41] & 42.3 & 0.36 & & 0.9 \\
\hline 31 & [41] & 37.2 & 0.39 & & 0.3 \\
\hline 32 & [41] & 22.8 & 0.35 & & 23 \\
\hline 33 & [39] & & & 250 & \\
\hline 34 & [42] & & & $>1000$ & \\
\hline 35 & [42] & & & 180 & \\
\hline
\end{tabular}

${ }^{\mathrm{a}}$ The fitting points are pharmacophore elements A-D and G.

compounds $\mathbf{2}$ and $\mathbf{3 4}$ it is obvious that a hydrogenbonding group in the tail is needed in order to obtain

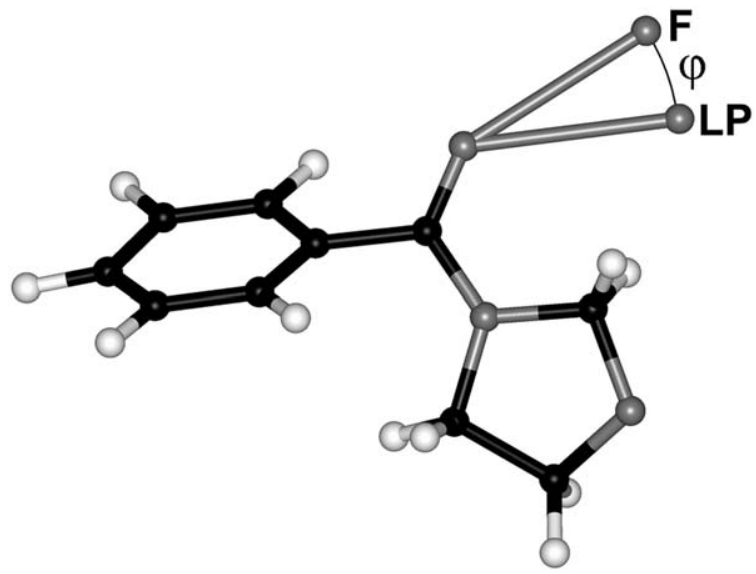

Figure 3. Definition of the angle $\varphi$ (the deviation from ideal hydrogen bond geometry). The head fragment of compound $\mathbf{4}$ is used as an example. LP is the vector in the direction of the lone pair. F is pharmacophore element F.

high NK2 affinity. Since a number of the high affinity NK2 antagonists do only have hydrogen bond acceptors in the tail (e.g. compounds 7, 22, 27, 28, 30 and 31), the simplest would be to assume that the interaction is one in which the receptor is the donor. However, with our previous method for superimposition [2] all attempts to add a hydrogen bond acceptor vector to the pharmacophore model failed because we 
Table 2. Data of compounds fitted to pharmacophore Models 2 and 3. Energy is the calculated conformational energy penalty for the putative bioactive conformation. $\mathrm{pK}_{\mathrm{a}}$ values are for the amine pharmacophore element D.

\begin{tabular}{|c|c|c|c|c|c|c|}
\hline \multirow{2}{*}{ Cpd. } & \multirow{2}{*}{ Ref. } & \multicolumn{2}{|c|}{ NK2 affinity } & \multicolumn{2}{|c|}{ Energy $(\mathrm{kJ} / \mathrm{mol})$} & \multirow{2}{*}{$\mathrm{pK}_{\mathrm{a}}$} \\
\hline & & $\mathrm{IC}_{50}(\mathrm{nM})$ & $\overline{\mathrm{K}_{\mathrm{i}}(\mathrm{nM})}$ & Model 2 & Model 3 & \\
\hline 1 & [43] & N.A. & N.A. & 11.8 & 11.9 & 8.9 \\
\hline 2 & [32] & & 0.5 & 13.9 & 14.7 & 9.1 \\
\hline 3 & [44] & & 23 & -5.3 & 8.4 & 9.0 \\
\hline 4 & [45] & 3.0 & & 9.5 & 7.6 & 8.9 \\
\hline 5 & [46] & & 23 & -2.2 & 7.6 & \\
\hline 6 & [47] & 11 & & 0.0 & 0.2 & 9.1 \\
\hline 7 & [39] & 8.9 & & 0.0 & 1.8 & 9.1 \\
\hline 8 & [48] & & 33 & -0.8 & 9.6 & 10.1 \\
\hline 9 & [49] & & 4.5 & 14.2 & 40.4 & 9.2 \\
\hline 10 & {$[50]$} & & 1.6 & 43.3 & 86.7 & 9.2 \\
\hline 11 & [51] & & 0.1 & 27.8 & 31.2 & 9.1 \\
\hline 12 & {$[50]$} & & 1.3 & 33.1 & 52.6 & 9.1 \\
\hline 13 & {$[52]$} & N. A. & N.A. & -4.5 & 9.6 & 9.0 \\
\hline 14 & {$[53]$} & 0.5 & & 67.5 & 102.0 & 7.6 \\
\hline 15 & [54] & & 0.6 & 8.3 & 0.0 & 8.3 \\
\hline 16 & [40] & 7.93 & & 5.2 & -7.9 & 9.0 \\
\hline 17 & [55] & 16.3 & & 7.9 & 0.2 & 9.0 \\
\hline 18 & [56] & N.A. & N.A. & 3.9 & 2.7 & 6.3 \\
\hline 19 & [57] & 2.2 & & 1.7 & 15.1 & 8.9 \\
\hline $20^{\mathrm{a}}$ & [58] & 4 & & 51.7 & 38.0 & - \\
\hline $20^{b}$ & [58] & 4 & & 0 & & - \\
\hline $20 a^{a}$ & [58] & 4 & & -8.1 & -1.3 & \\
\hline 21 & [59] & 8.9 & & 6.2 & 0.5 & 9.0 \\
\hline
\end{tabular}

${ }^{\mathrm{a}}$ Conformation $1{ }^{\mathrm{b}}$ Conformation 2.

did not allow the vector to deviate from the ideal lone pair direction. Therefore the procedure described in the Computational methods section was adopted.

The tail fragments have the same conformation in all three pharmacophore models, therefore the hydrogen bond interaction vector also has the same position in the three models. Compounds 2, 7, 16, and 22-32 (Figure 5) were superimposed on the previous model using pharmacophore elements A-D as fitting points. A dummy atom was placed $2.8 \AA$ from the hydrogen bond acceptor in the direction of the lone pair. The coordinates of the hydrogen bond interaction vector (pharmacophore element $\mathrm{G}$ ) were defined as the average position of the acceptor and dummy atoms respectively in the superimposition of compounds $\mathbf{2}$, 7, 16, and 22-32.

Pharmacophore Models 1-3 and the coordinates of the pharmacophore elements are shown in Figures 6-8. Figure 9 shows a superimposition of the three pharmacophore models. The positions of pharmaco- phore elements B, C and D are identical in all three models. In Model 1, pharmacophore elements A and $\mathrm{B}$ are in a parallel displaced and tilted conformation. In Model 2, pharmacophore elements $\mathrm{A}$ and $\mathrm{B}$ are in a parallel displaced conformation, whereas they are in an edge to ring face conformation in Model 3 [3].

\section{Compounds and pharmacophore elements}

The set of compounds 1-21 was chosen for its structural diversity and it contains high affinity selective NK2, dual NK1/NK2 and triple NK1/NK2/NK3 antagonists. Compounds 2-17 and 19-21 were also used to derive or evaluate our previous model [2]. Two or three hydrophobic groups are found in all NK2 antagonists (pharmacophore elements A, B and C; Figure 1). A basic amino group is also present in all structures (pharmacophore element D, represented as a vector in Figure 2) except for compound 20 [2]. Pharmacophore elements A and B are connected by a linker holding a hydrogen bond acceptor (pharmacophore elements $\mathrm{E}$ and $\mathrm{F}$ ). In most cases this is a carbonyl or ether oxygen. Furthermore, a hydrogen bond acceptor is found in the tail part of most NK2 antagonists (pharmacophore element G). The hydrophobic groups are marked in Figure 4 by centroids, the basic nitrogen is marked with a ' + ' sign and the hydrogen bond acceptors are marked by bold type atom labels.

The pharmacophore element labelled B (Figure 1) is found to be an aromatic ring in all structures except compounds 10-12. These compounds have electronegative groups in this area. Compound $\mathbf{1 0}$ has a hydroxy group, compound $\mathbf{1 1}$ a methoxy group and compound 12 a carbonyl group. The pharmacophore element A does not need to be an aromatic ring but can be aliphatic or olefinic hydrophobes as is the case for compounds $1,6,14$, and 15 . In compounds 1,14 , and 15 , the aromatic pharmacophore element $\mathrm{C}$ is lacking.

The hydrogen bond acceptor in the head fragment (pharmacophore elements $\mathrm{E}$ and $\mathrm{F}$ ) is present in all compounds. Compounds $\mathbf{3}$ and $\mathbf{2 0}$ have only been fitted to pharmacophore element $\mathrm{E}$, whereas compounds 5 and $\mathbf{1 3}$ have only been fitted to pharmacophore element F. The rest of the compounds could be fitted to both pharmacophore elements E and F. However, in the ligand-receptor complex, both interactions represented by the pharmacophore element $\mathrm{E}$ and $\mathrm{F}$ may not be present (See section The receptor models below).

The hydrogen bond acceptor in the tail (pharmacophore element $\mathrm{G}$ ) is lacking in compounds 8, 10-12, 

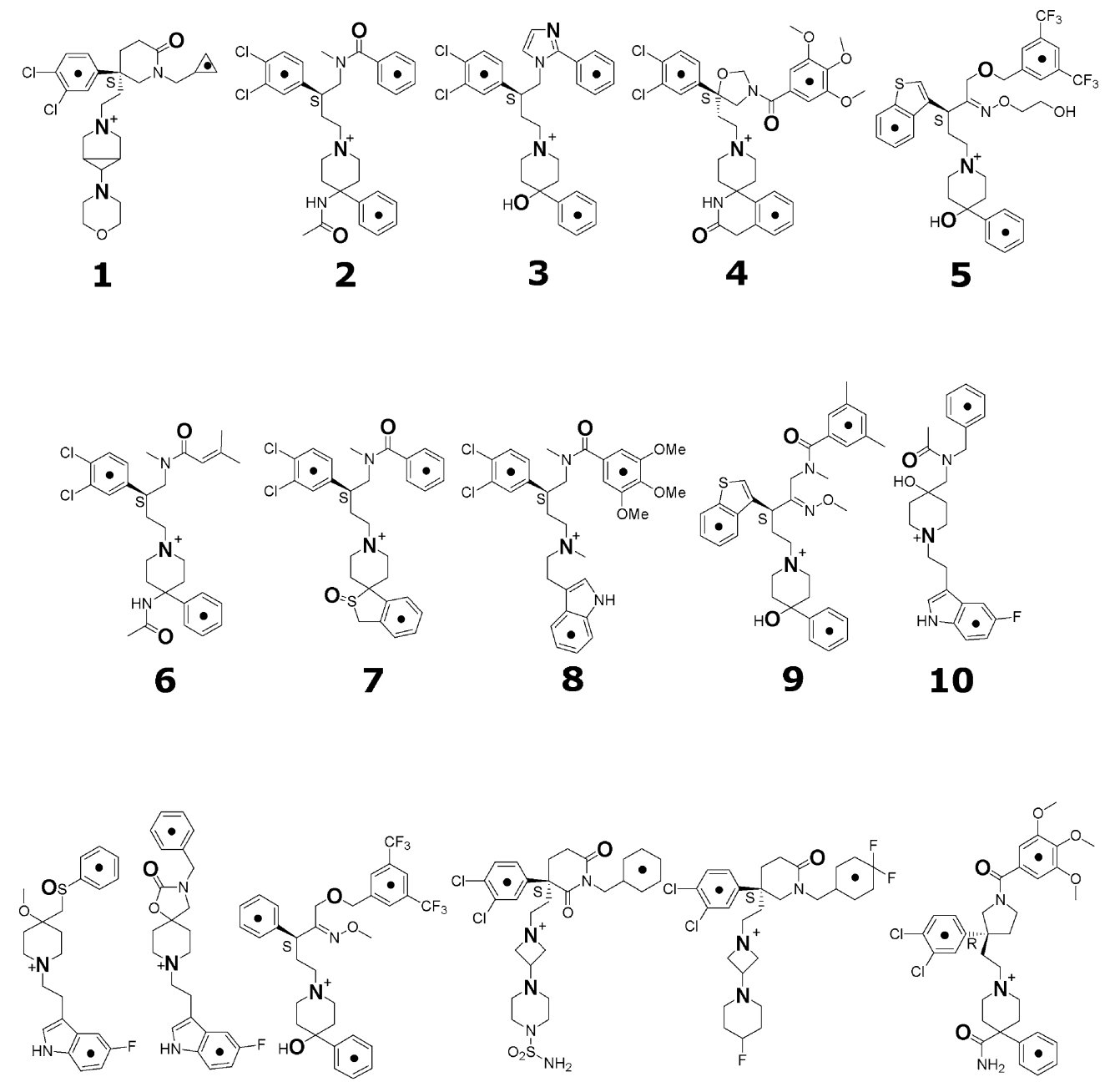

11

1213

14

15

16

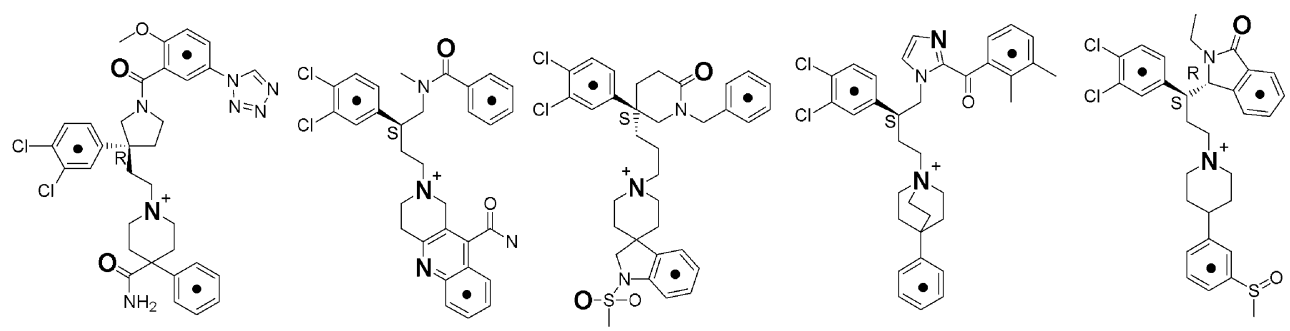

$17 \quad 18 \quad 19$

21

Figure 4. Compounds 1-21 were fitted to the pharmacophore models. Centroids, '†' and atoms in bold mark the selected pharmacophore elements. The atoms in bold are hydrogen bond acceptors or donors. Data and references are given in Table 2. 


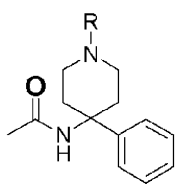<smiles>[R]N1CCC2(CC1)NC(=O)Cc1ccccc12</smiles>

24

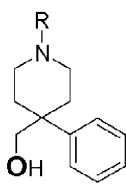

29

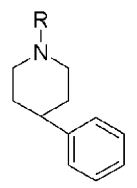

34<smiles>[R]N1CCC2(CC1)c1ccccc1CS2=O</smiles>

7<smiles>[R]N1CCC2(CC1)c1ccccc1CCN2C(C)=O</smiles>

25<smiles>[R]N1CCC(OCC)(c2ccccc2)CC1</smiles>

30<smiles>[R]N1CCC2CCC1C2</smiles>

35<smiles>NC(=O)C1(c2ccccc2)CCN(c2ccccc2)CC1</smiles>

16<smiles>[R]N1CCC(O)(c2ccccc2)CC1</smiles>

26

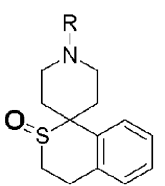

22<smiles>[R]N1CCC2(CC1)OCc1ccccc12</smiles>

27<smiles>[R]N1CCC2(CC1)OCCc1ccccc12</smiles>

28<smiles>CC(=O)OC1(c2ccccc2)CCN(CC(=O)NCC2(c3ccccc3)CCNCC2)CC1</smiles><smiles>O=C1CCc2ccccc2C1</smiles>

33<smiles>CCC1(c2ccc(Cl)c(Cl)c2)CCN(C(=O)c2cc(OC)c(OC)c(OC)c2)C1</smiles>

R2

Figure 5. Compounds 2, 7, 16, 22-32 were used to derive the position of pharmacophore element G. Atoms in bold mark the selected hydrogen bond acceptor pharmacophore elements. Data and references are given in Table 1.

15, and 20. The basic amino group is protonated at physiological $\mathrm{pH} . \mathrm{pK}_{\mathrm{a}}$ calculations using MolSurf 99/1 [30] (Table 2) show that in all compounds having pharmacophore element $\mathrm{D}$, this nitrogen always has the highest $\mathrm{pK}_{\mathrm{a}}$ value.

\section{Evaluation of the pharmacophore models}

Compounds 2, 7, 16 and 22-32 (Figure 5) were fitted to Model 1 by the procedure described under Computational methods. The angles ( $\varphi$ defined in Figure 3 ) between the lone pair of the hydrogen bond acceptor atom, and pharmacophore element $\mathrm{G}$ are shown in Table 1 as well as the RMS values. It has been shown that the direction of hydrogen bonds involving an ether oxygen does not have a strong preference for the direction of the lone pairs [31]. The strength of the hydrogen bond in the plane between the lone pairs does not vary significantly with the angle $\varphi$. Hydrogen bonds involving a ketone oxygen have a lone pair preference. However, this preference is small in the plane between the lone pairs. A $\varphi$ angle of $60^{\circ}$ is calculated to reduce the strength of the hydrogen bond to approximately $80 \%$ compared to that of a hydrogen bond in the lone pair direction [31]. Only compound 24 exceeds this deviation. A superimposition of the tail fragments of compounds 2, 7, 16 and 22-32 is shown in Figure 10.

Compounds 1-21 were fitted to both pharmacophore Models 2 and 3 as described in the Computational methods section. RMS values and the deviations of the hydrogen bond interaction vectors from the ideal geometry are shown in Table 3 . Figure 11 shows a superimposition of compounds 1-9 and 13-21 fitted to pharmacophore Model 2 (compounds 10-12 are 

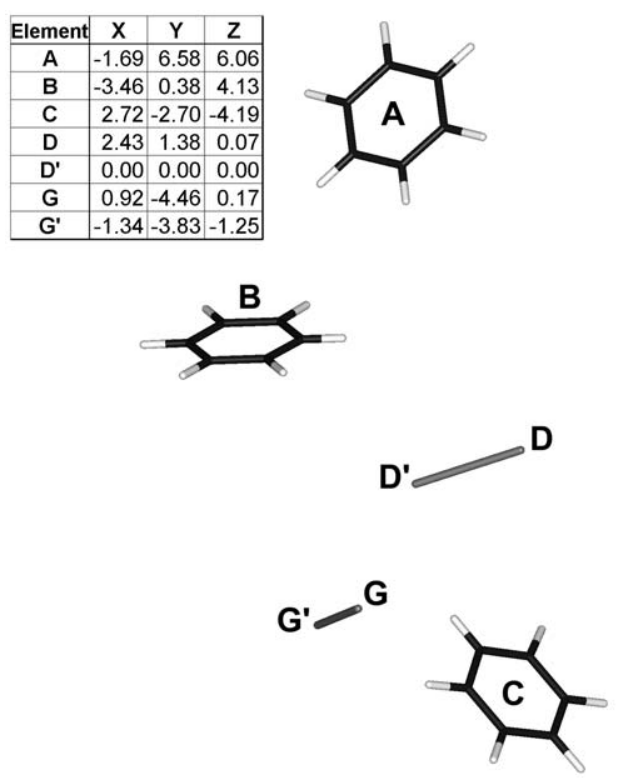
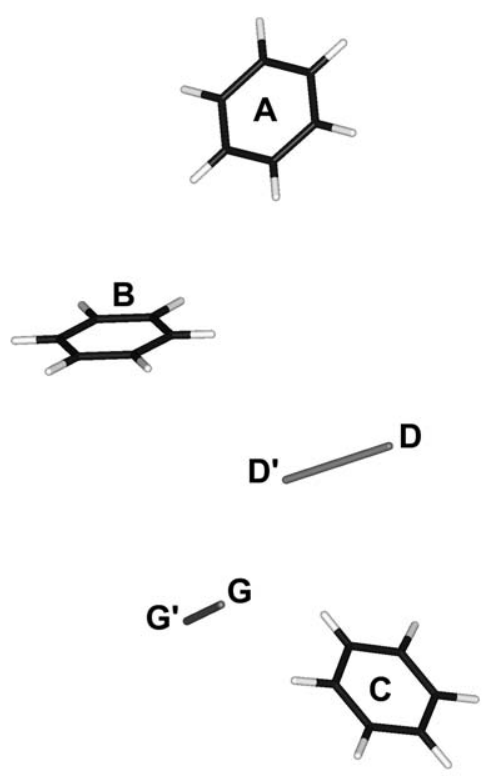

Figure 6. Pharmacophore Model 1. Stereo image. The coordinates for the pharmacophore elements are shown in the box. $\mathrm{G}^{\prime}$ is the acceptor atom of the hydrogen bond acceptor pharmacophore element. $\mathrm{D}^{\prime}$ is the hydrogen bond donor atom of the hydrogen bond donor pharmacophore element.
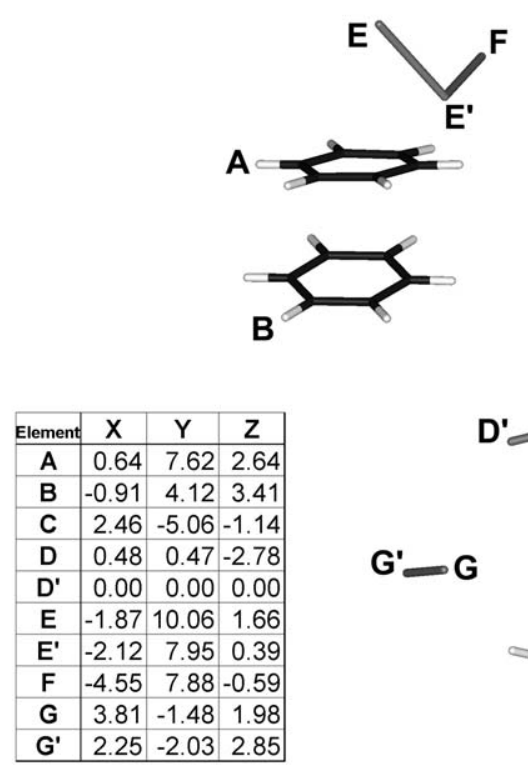

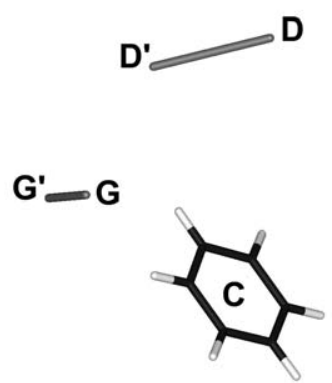

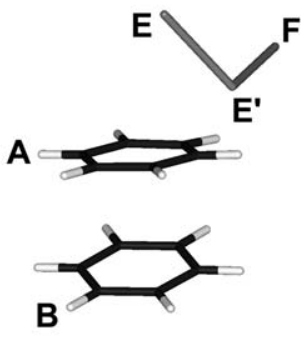

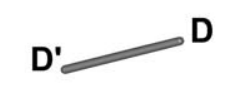

$\mathbf{G}^{\prime}-\mathbf{G}$

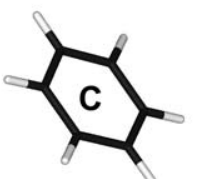

Figure 7. Pharmacophore Model 2. Stereo image. The coordinates for the pharmacophore elements are shown in the box. $\mathrm{E}^{\prime}$ and $\mathrm{G}^{\prime}$ are the acceptor atoms of the hydrogen bond acceptor pharmacophore elements. $\mathrm{D}^{\prime}$ is the hydrogen bond donor atom of the hydrogen bond donor pharmacophore element. 


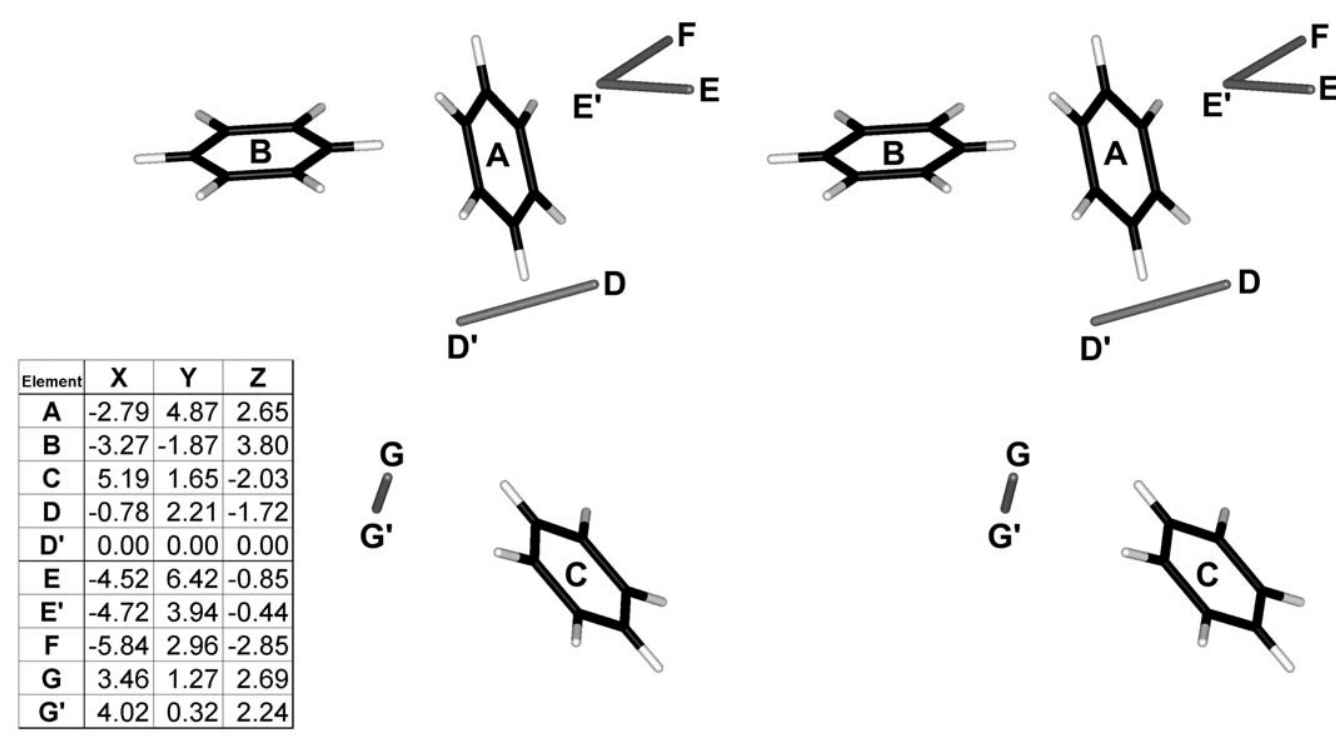

Figure 8. Pharmacophore Model 3. Stereo image. The coordinates for the pharmacophore elements are shown in the box. $\mathrm{E}^{\prime}$ and $\mathrm{G}^{\prime}$ are the acceptor atoms of the hydrogen bond acceptor pharmacophore elements. $\mathrm{D}^{\prime}$ is the hydrogen bond donor atom of the hydrogen bond donor pharmacophore element.

believed to have another binding mode, as described below). Figure 12 shows a superimposition of the same compounds fitted to pharmacophore Model 3.

Compounds 1-3, 6-8, 13, and 15, 16, 18 and 19 could be fitted to both Model 2 and 3 with low conformational energies and low RMS values (Tables 2 and 3). Compounds 4, 5, 9, 17, 20 and 21 have high RMS values when calculated over all pharmacophore elements. However, if pharmacophore element A is excluded from the RMS calculation, these compounds all have an acceptably low RMS value. Some compounds have large substituents in the aromatic ring that maps to pharmacophore element A (e.g. compounds 16 and 17) and some have a bulky aliphatic ring (e.g. compounds 14 and $\mathbf{1 5}$ ). It is therefore reasonable to assume that the centroid of pharmacophore element $\mathrm{A}$ is not located exactly in the same place within the receptor for all the compounds examined, but rather falls within the same area.

We have previously shown that the force fields MMFFs, MM2 and AMBER are unable to correctly calculate the conformational energy penalty of compound $\mathbf{1 4}$ due to an 'electrostatic collapse' [2]. Since the structurally related compound $\mathbf{1 5}$ could be fitted to both models with a low conformational energy, we assume that compound $\mathbf{1 4}$ can also be fitted to both models with a low conformational energy and that the high calculated energy is a computational artefact.
Two conformations of compound $\mathbf{2 0}$ could be fitted to pharmacophore Model 2. The main difference between the conformations are the torsional angle of the bond connecting the carbonyl carbon to the imidazole ring. In conformation 1 , the carbonyl can be superimposed on the carbonyl in the head fragment of compound 2 whereas it is pointing in the opposite direction in conformation 2. Only conformations for which the carbonyl is superimposable on compound 2 can be fitted to Model 3. In compound 20, the imidazole nitrogen is assumed to be involved in hydrogen bonding to the receptor. The nitrogen can be a hydrogen acceptor (unprotonated imidazole as for compound 20) or donor (protonated imidazole as in compound 20a in Table 2). Whether the nitrogen acts as a donor or acceptor has a large impact on the torsional energy of the bond connecting the carbonyl carbon to the imidazole ring. A torsional drive of this angle of the model system shown in Figure 13 was performed by using MMFFs and B3LYP/6-31G**. The energy profile calculated by MMFFs compares well with that of the DFT method for both the neutral and protonated systems. The torsional barrier of the protonated system is lower than that of the neutral system, and the profiles as calculated by both methods are different for the two model systems. When conformation 1 of compound 20 is fitted to Models 2 and 3 this angle (defined in Figure 13 for the model system) is $144.3^{\circ}$ and $131.2^{\circ}$, respectively. By assuming that the 

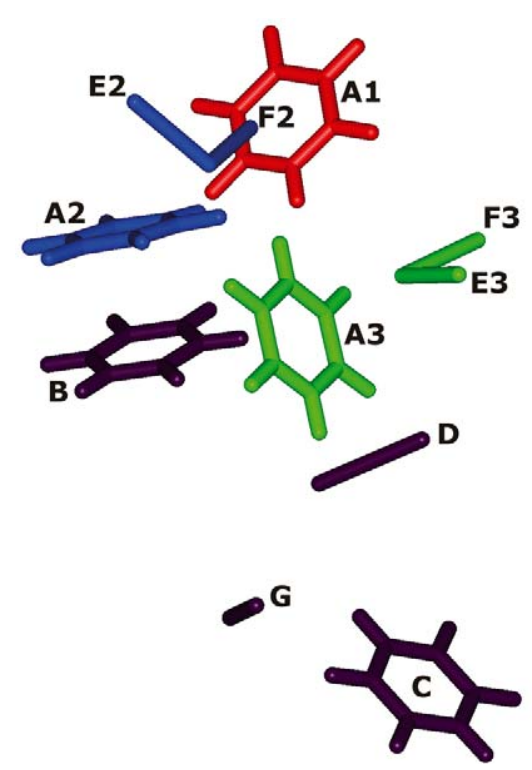
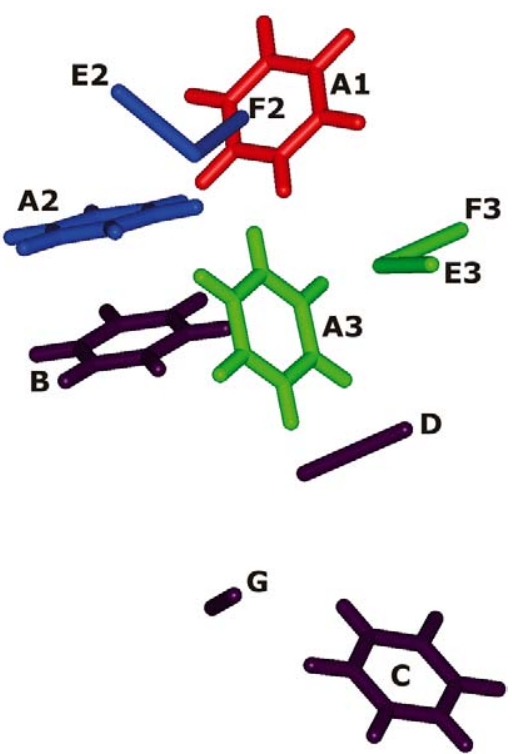

Figure 9. Stereo image. A superimposition of pharmacophore Models 1-3. Black: the pharmacophore elements B, C, D and G have the same position in the three models. Red: Model 1. Blue: Model 2. Green: Model 3.

imidazole acts as a hydrogen bond donor, 20a could be fitted to both models with a low conformational energy penalty. It is not unreasonable to assume that pharmacophore element $\mathrm{E}$ is a hydrogen bond donor as well as an acceptor if the hydrogen bond is formed to a water molecule or to a residue with a side chain that can act as both hydrogen bond donor and acceptor. However, compound 20 has a permanent positive charge, and therefore it is unlikely to be protonated. This suggests that conformation 2 is the bioactive conformation and therefore compound $\mathbf{2 0}$ can be fitted to Model 2 but not Model 3 with a low conformational energy penalty.

Compound 9 could be fitted to Models 2 and 3 , but only to Model 2 with a low conformational energy. Compound 21 could be fitted to Models 1 and 2 but not to Model 3. When fitted to Model 3 the ethyl substituent in the 2-position of the 2,3dihydro-isoindol-1-one group would fall in the area of pharmacophore element $\mathrm{A}$. The aromatic part of the 2,3-dihydro-isoindol-1-one group could only map the pharmacophore model when the stereochemistry was inverted at the 3-position, and the ring could not be fitted in a coplanar orientation. Compounds 10-12 were fitted to Model 1 with a low conformational energy and a low RMS value [2]. However, they could only be fitted to Models 2 and 3 with a high conformational energy and high RMS. Structurally these compounds differ from the rest as previously described.
The angle ( $\varphi$ defined in Figure 3 ) between the lone pair of the hydrogen bond acceptor atom, and pharmacophore elements E, F and G is shown in Table 3. Only compounds 9-12 have a large angle for pharmacophore element $\mathrm{E}$ while the angle $\varphi$ for pharmacophore element $\mathrm{G}$ is large for compounds $\mathbf{4}$ and $\mathbf{1 8}$. The angle $\varphi$ for pharmacophore element D is also shown in Table 3. Except for compounds 11-12 this angle is small for all compounds.

If the amide in the head of compound 2 is demethylated, the affinity for the NK2R drops by more than a factor of 200 [32]. There are three possible explanations for this. (1) There could be a favourable interaction between the methyl group and the receptor. (2) The de-methylated compound has a more negative solvation energy (by $13.9 \mathrm{~kJ} / \mathrm{mol}$ using PM3/SM5.4 and by $5.1 \mathrm{~kJ} / \mathrm{mol}$ using MMFFs+GB/SA) that is not counteracted by a favourable interaction with the receptor. (3) For compound 2 low energy conformations exist where the amide adopts either a cis or a trans conformation. When compound 2 is demethylated only the trans conformation is found in low energy conformations. A dihedral drive around the amide gives a difference of $23.6 \mathrm{~kJ} / \mathrm{mol}$ between the cis and trans conformation whereas this difference is only $1.8 \mathrm{~kJ} / \mathrm{mol}$ for the methylated compound (MMFFs+GB/SA). Therefore the methyl group serves to make the cis conformation energetically accessible. 

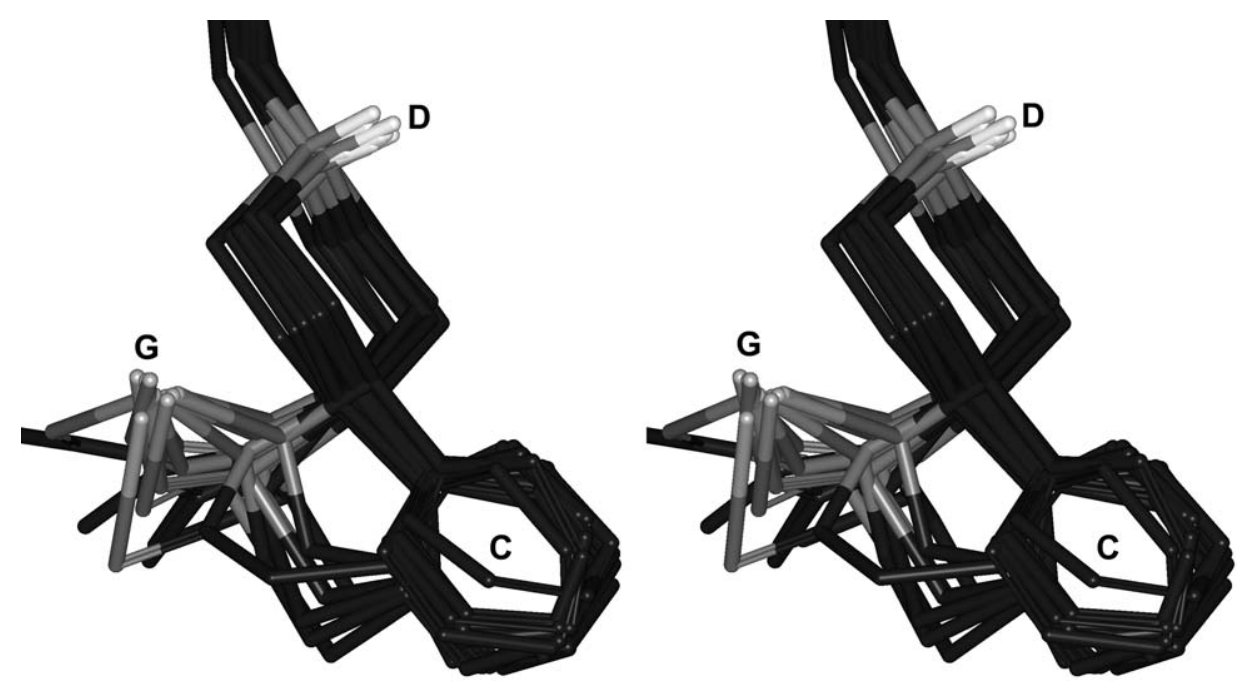

Figure 10. Superimposition of compounds 2, 7, 16 and 22-32. Stereo image, hydrogens are removed for clarity. The hydrogen bond acceptor pharmacophore element $\mathrm{G}$ is shown as vectors.

If the third explanation is correct, Model 1 cannot represent the actual binding mode.

Summarising the present section we suggest that Model 2 represents the best pharmacophore model for the examined NK2 antagonists. Model 2 includes all the pharmacophore elements necessary for high affinity and only compounds $\mathbf{1 0}-\mathbf{1 2}$ could not be fitted to this model with a low RMS and a low conformational energy penalty. We believe that the compounds 10-12 bind to the receptor in a different mode.

\section{The receptor models}

It was verified that the NKR 7TM receptor models were compatible with the zinc ion binding sites found by Elling et al. [7, 8] and the Asp79Asn + Asn303Asp double mutant by Donnelly et al. [9]. The compounds were fitted to pharmacophore Model 2 before being docked into the receptor model followed by minimisation of the ligand-receptor complex. The conformation of the flexible linker connecting the head and tail part of the antagonists was changed upon docking. However, the conformational changes of the head and tail fragments were minor. Conformations fitted to pharmacophore Models 1 and 3 were found to be incompatible with the receptor models. Pharmacophore element A was found to clash with the receptors in conformations fitted to either Model 1 or 3.

The proposed antagonist binding sites of the NK1R and NK2R models binding compound $\mathbf{1 6}$ are shown in Figure 14. The residues identified by site directed mutagenesis as important for the binding of compound
2 and $\mathbf{1 6}$ to the NK2R are M117, Q166, H198, Y266, F270 and Y289 [4, 15, 28]. The residues important for the binding of compound $\mathbf{1 6}$ to the NK1R are Q165, H197, I204, F264 and H265 [4]. Compound $\mathbf{1 6}$ is docked in the NK2R model so that it makes a direct interaction with the above mentioned residues. In the NK1R model, compound $\mathbf{1 6}$ also has direct interactions with the residues identified by site directed mutagenesis. Furthermore, an interaction with Y287 is found. It is evident that the location of the binding site in our NK1R and NK2R models is the same and that the conformations of the antagonists docked into the NK1 R and NK2R models are almost identical. This conclusion is the opposite of that of Greenfeder et al. [4] who conclude that the binding sites of the NK1R and NK2R differ, and that the conformations of compound $\mathbf{1 6}$ bound to the NK1R and the NK2R are different.

\section{Predictions made from the NKR models}

When docked into the NK2R model the compounds in this study except 10-12 were found to bind in a conformation represented by pharmacophore Model 2 . However, the linker connecting the head and the tail part of the antagonists has a different conformation when docked in the NKRs as compared to the conformations fitted to Model 2. Therefore the head and tail fragments have the same conformation but different relative orientations in the docked conformations as compared to pharmacophore Model 2. For each pharmacophore element except $\mathrm{F}$ a favourable interac- 

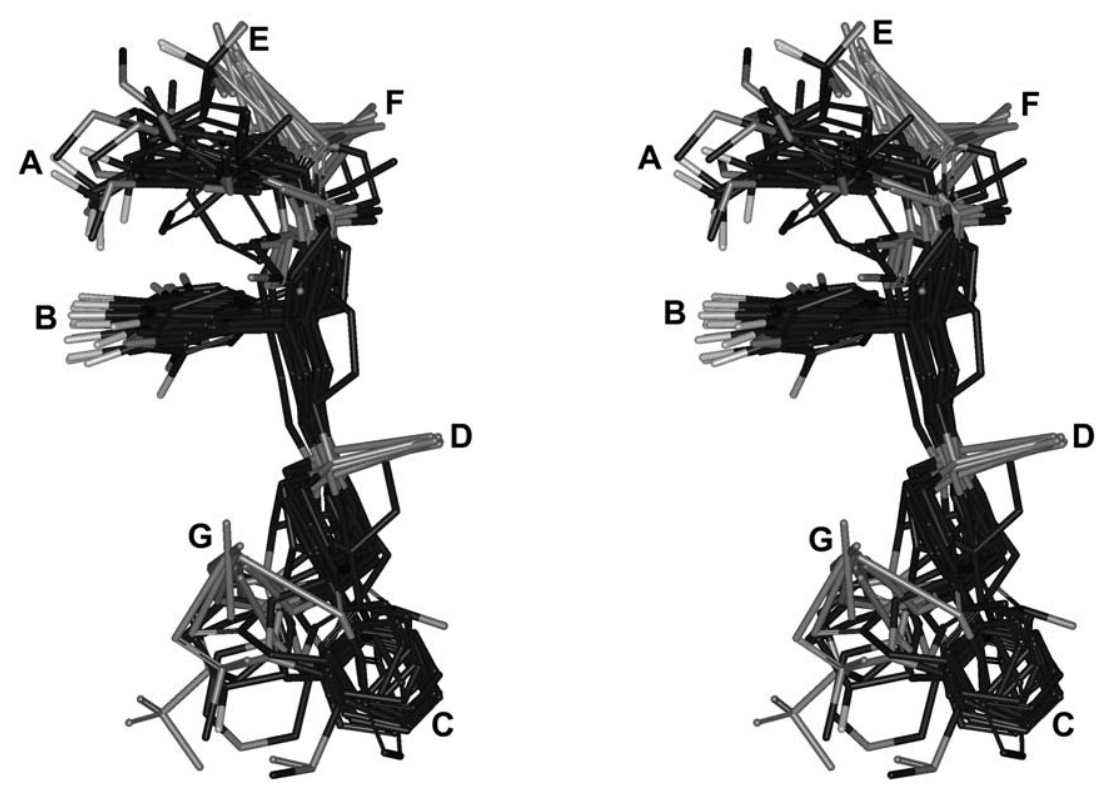

Figure 11. Superimposition of compounds 1-9 and 13-21 fitted to Model 2. Stereo image, hydrogens are removed for clarity. The hydrogen bond donor and acceptor pharmacophore elements D, E, F and $\mathrm{G}$ are shown as vectors.

tion with the receptor was identified. These are shown in Figure 14. This suggests that pharmacophore Model 2 excluding pharmacophore element $\mathrm{F}$ represents the actual binding mode.

The NK2R model and mutational data [28] indicate that compounds $\mathbf{1 0 - 1 2}$ bind in the same area as the rest of the compounds in this study, but in a different orientation. Manual docking of compound 20a into our NK2R model suggests that two hydrogen bonds can be formed from Gln 166 to the protonated nitrogen and the benzyl oxygen. However, as discussed above it is unlikely that compound $\mathbf{2 0}$ is protonated and it is more reasonable to assume that only one hydrogen bond is formed.

The NK2R model indicates that pharmacophore element $\mathrm{E}$ interacts with a proton in the amide group of the sidechain of Gln166 (Figure 14). Glutamine is a flexible residue so the angle $\varphi$ between the lone pair of the ligand and the proton on Gln166 may be significantly smaller than the value in Table 3 . Pharmacophore element $G$ interacts with Tyr289 in the NK2R (Figure 14). Since tyrosine can act as both a hydrogen bond donor and acceptor it is possible that Tyr289 interacts with a hydrogen on the amide group in the tail of compounds $\mathbf{4}$ and 18. This would result in a lower $\varphi$ value than given in Table 3. Pharmacophore element D also interacts with a tyrosine (Tyr266 in the NK2R). Therefore we are unable to conclude whether the basic nitrogen is protonated or not when the ligands bind to the receptor.

In the conformation of compound $\mathbf{2}$ docked into the receptor models, the amide in the head fragment is in a cis conformation. No specific interactions are observed between the methyl group on the amide, and the NK2R model. In the de-methylated analogue of compound 2 specific interactions between the amide and the NK2R model were also absent. Therefore the role of the methyl group is either conformational (to make the cis conformation energetically available) or to lower the solvation energy.

\section{Selectivity for the NK1, NK2 and NK3 receptors}

The most important information provided by a pharmacophore model is the putative bioactive conformation of each ligand and the alignment of these conformations. A correct molecular alignment makes it possible to identify the structural relationships between different types of ligands. Receptor subtype selectivity may arise either from differences in the bioactive conformations at the receptor subtypes, or from different substitution patterns. We believe the latter is true for NK1/NK2 subtype selectivity. Table 4 shows the NK subtype selectivity for two head fragments. Selective NK1, selective NK2, dual NK1/NK2 and triple NK1/NK2/NK3 antagonists can be obtained from the same scaffold. The subtype selectivity is 
Table 3. Data of compounds fitted to pharmacophore Models 2 and 3. Angle is the deviation from ideal hydrogen bond geometry ( $\varphi$ as defined in Figure 3).

\begin{tabular}{|c|c|c|c|c|c|c|c|c|c|c|}
\hline \multirow{3}{*}{ Cpd. } & \multicolumn{5}{|c|}{ Model 2} & \multicolumn{5}{|c|}{ Model 3} \\
\hline & \multicolumn{4}{|c|}{ Angle $\left(^{\circ}\right)$} & \multirow{2}{*}{$\begin{array}{l}\text { RMS } \\
\left(\AA^{\mathrm{a}}\right)\end{array}$} & \multicolumn{4}{|c|}{ Pharmacophore element } & \multirow{2}{*}{$\begin{array}{l}\text { RMS } \\
\left(\AA^{\mathrm{a}}\right)\end{array}$} \\
\hline & $\mathrm{D}$ & $\mathrm{E}$ & F & G & & $\mathrm{D}$ & $\mathrm{E}$ & $\mathrm{F}$ & $\mathrm{G}$ & \\
\hline 1 & 23.3 & 37.2 & 9.5 & 49.9 & 0.44 & 15.2 & 28.9 & 18.0 & 36.0 & 0.25 \\
\hline 2 & 12.0 & 28.8 & 11.8 & 49.0 & 0.43 & 0.0 & 27.2 & 10.0 & 43.2 & 0.47 \\
\hline 3 & 0.0 & 27.5 & - & 13.9 & 0.19 & 0.0 & 13.7 & - & 15.6 & 0.24 \\
\hline 4 & 14.6 & 27.9 & 25.7 & 101.3 & (0.60) 0.84 & 14.5 & 25.9 & 25.4 & 103.5 & (0.41) 0.92 \\
\hline 5 & 15.4 & - & 36.5 & 41.8 & (0.47) 0.74 & 0.0 & - & 13.9 & 14.2 & 0.35 \\
\hline 6 & 11.8 & 7.7 & 7.4 & 59.0 & 0.44 & 0.0 & 25.4 & 12.7 & 64.1 & 0.41 \\
\hline 7 & 0.0 & 0.0 & 0.0 & 0.0 & 0.46 & 8.3 & 25.4 & 4.8 & 34.8 & 0.31 \\
\hline 8 & 0.0 & 0.0 & 0.0 & - & 0.46 & 5.0 & 26.2 & 5.1 & - & 0.29 \\
\hline 9 & 14.2 & 74.9 & 68.4 & 17.2 & (0.52) 0.69 & 52.4 & 18.2 & 80.7 & 55.4 & 0.44 \\
\hline 10 & 76.6 & 84.4 & 81.8 & - & 0.92 & 27.3 & 74.5 & 72.8 & - & 0.66 \\
\hline 11 & 42.6 & 67.1 & 57.6 & - & 0.62 & 24.4 & 29.2 & 44.4 & - & 1.52 \\
\hline 12 & 40.1 & 8.9 & 80.0 & - & 1.08 & 66.6 & 57.5 & 37.2 & - & 0.56 \\
\hline 13 & 13.9 & - & 39.2 & 37.0 & 0.63 & 0.0 & - & 16.5 & 22.2 & 0.29 \\
\hline 14 & 11.8 & 32.6 & 23.0 & 27.6 & (0.39) 0.63 & 30.8 & 49.2 & 14.1 & 51.3 & 0.40 \\
\hline 15 & 13.2 & 33.5 & 20.6 & 39.3 & 0.48 & 52.9 & 54.9 & 0.0 & 6.8 & 0.35 \\
\hline 16 & 20.3 & 35.2 & 51.8 & 39.9 & 0.46 & 20.0 & 31.8 & 13.7 & 14.5 & 0.86 \\
\hline 17 & 17.0 & 21.0 & 14.6 & 31.3 & (0.60) 0.89 & 17.3 & 29.6 & 14.8 & 13.6 & (0.45) 0.76 \\
\hline 18 & 26.2 & 35.7 & 23.3 & 77.0 & 0.27 & 20.4 & 18.2 & 3.3 & 82.2 & 0.45 \\
\hline 19 & 18.7 & 25.9 & 99.6 & 55.5 & (0.47) 0.56 & 5.8 & 9.8 & 55.4 & 30.2 & 0.71 \\
\hline $20^{b}$ & - & 40.5 & - & - & 0.92 & - & 49.4 & - & - & 0.42 \\
\hline $20^{c}$ & - & 5.4 & - & - & 0.75 & & & & & \\
\hline $20 a^{b}$ & - & 5.1 & - & - & (0.27) 0.74 & - & 17.8 & - & - & 0.82 \\
\hline 21 & 14.0 & 37.4 & 25.9 & - & 0.97 & 10.4 & 33.4 & 46.9 & - & $(0.18)$ \\
\hline
\end{tabular}

${ }^{\mathrm{a}}$ The fitting points are pharmacophore elements A-G. Numbers in parentheses are RMS without pharmacophore element $\mathrm{A}$ as fitting point.

${ }^{\mathrm{b}}$ Conformation 1.

${ }^{\mathrm{c}}$ Conformation 2 .

determined by the substitution pattern of the pharmacophore elements A, B and C. An unsubstituted phenyl ring and a 3,4-di-chlorophenyl as pharmacophore elements A and B, respectively, is optimal for NK2 activity [33, 34]. 3,5-Di-methylphenyl, 3,5-ditrifluoromethylphenyl and 3,4,5-tri-methoxyphenyl as pharmacophore element A is optimal for NK1 activity whereas substituents in pharmacophore element B are of minor importance for NK1 activity [33, 35, 36]. Subtle changes around pharmacophore elements $\mathrm{C}$ and $\mathrm{G}$ also seem to be important for subtype selectivity. Of the different compounds examined only compounds 10-12 and $\mathbf{2 1}$ have a scaffold that is not claimed to have both NK1 and NK2 activities. We concluded earlier that compounds 10-12 have another binding mode than the rest of the compounds. The head fragment of compound $\mathbf{2 1}$ is for NKR antagonists to our knowledge unique for this compound.
Therefore all the scaffolds (except one) from which we have built the NK2 pharmacophore models can also have NK1 activity. It is likely that the bioactive conformations of the NK1R and NK2R subtypes are very similar and that our pharmacophore models are dual NK1/NK2 pharmacophore models. This is supported by the receptor model (Figure 14). In the NK1R model, Thr201 is located in the binding pocket for the trimethoxyphenyl group of compound 16. The equivalent residues in the NK2R and NK3R are Ile202 and Ile252, respectively. Since threonine is polar, as opposed to isoleucine, this could explain the subtype difference in the observed SAR around pharmacophore element A.

Reversing the amide group in the tail of compound 2 increases NK3 activity [37]. However, potent and selective NK3 antagonists have a reversed amide group in the linker holding pharmacophore elements A, B, 

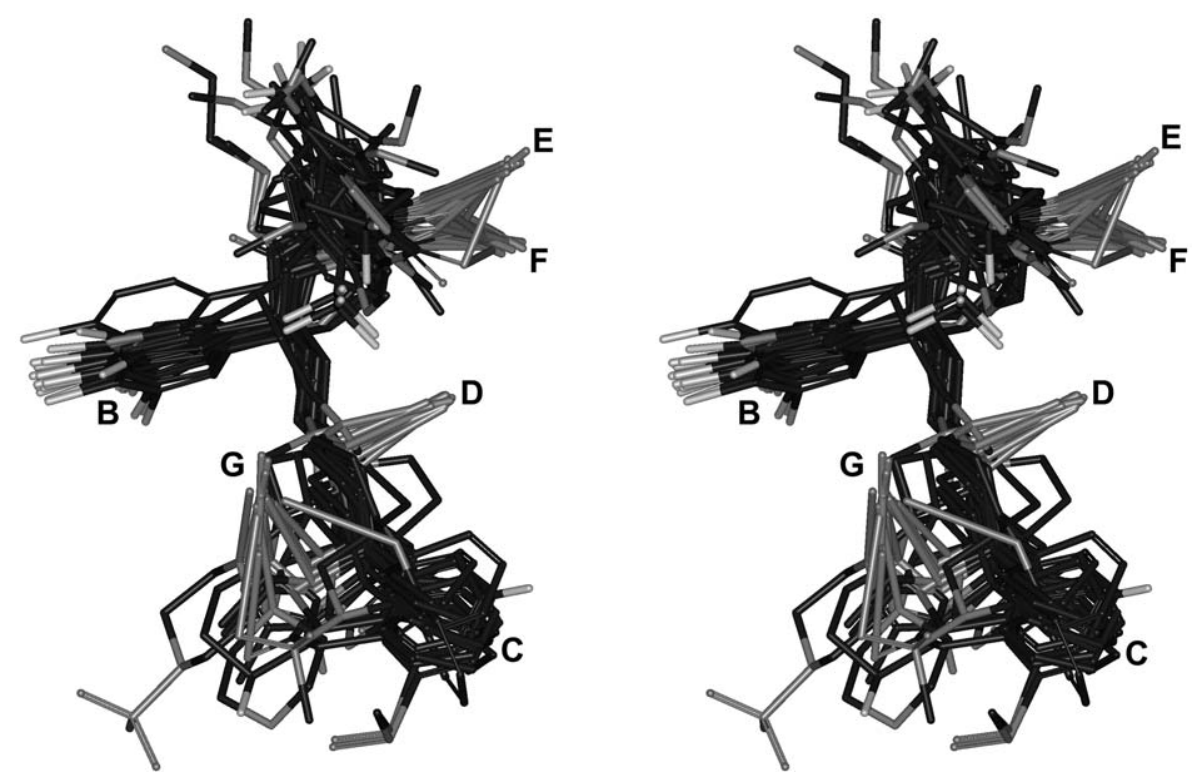

Figure 12. Superimposition of compounds 1-9 and 13-21 fitted to Model 3. Stereo image, hydrogens are removed for clarity. The hydrogen bond donor and acceptor pharmacophore elements D, E, F and G are shown as vectors.
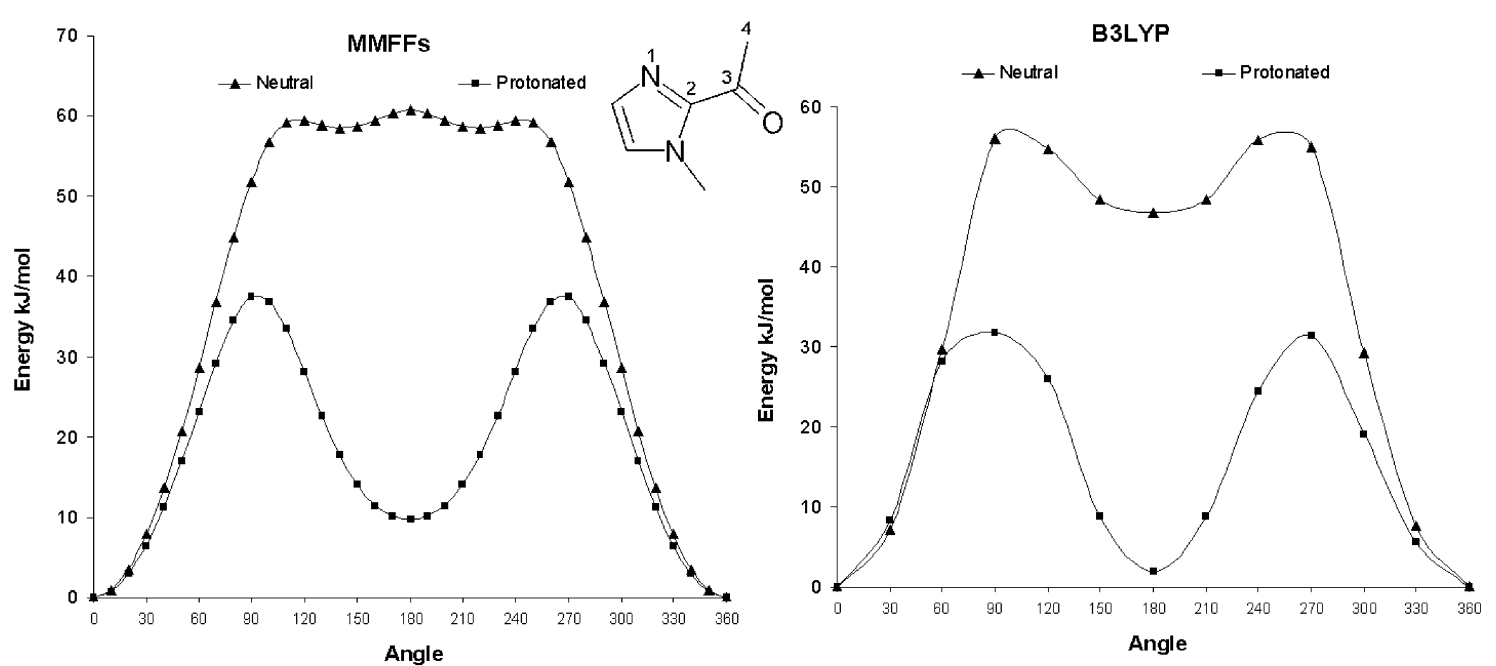

Figure 13. Torsional drive of the angle 1-2-3-4 in the model system for the head fragment of compound 20.

$\mathrm{E}$ and $\mathrm{F}$ (cf. compound $\mathbf{2}$ with $\mathbf{3 7}$ and compound $\mathbf{1 9}$ with 36 in Figure 4 and Table 4) [37, 38]. Changing the position of the carbonyl from that in compound 2 to that in $\mathbf{3 7}$ changes the conformational properties of the head fragment considerably, but the change of the carbonyl position from that in compound $\mathbf{1 9}$ to that in $\mathbf{3 6}$ has only a minor effect on the conformations. The selective NK3 antagonists also differ from the NK2 antagonists in the length of the linker connecting the head and the tail fragments. In the examined NK2 antagonists (except compound 19) the linker is a $\mathrm{C} 2$ chain whereas it is a $\mathrm{C} 3$ chain in the selective NK3 antagonists. Compound $\mathbf{3 6}$ could be fitted to all pharmacophore models while compound $\mathbf{3 7}$ could not be fitted to any of the models. However, if pharmacophore elements $\mathrm{E}$ and $\mathrm{F}$ are ignored compound $\mathbf{3 7}$ can be fitted to Model 2. These observations suggest that the bioactive conformations of NK antagonists at the NK2R and NK3R subtypes could be different or that the carbonyl in compound $\mathbf{3 7}$ is interacting with another residue. Pharmacophore element $\mathrm{E}$ is forming a hydrogen bond to Glu166 in the NK2R. The equiva- 
Table 4. SAR of two NK antagonist head fragments and two selective NK3 antagonists.

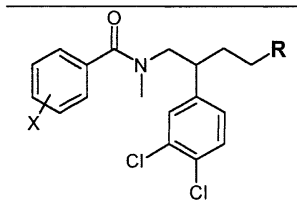

$\mathrm{X}$

NK1 $\mathrm{IC}_{50}(\mathrm{nM})$

$\mathrm{NK} 2 \mathrm{IC}_{50}(\mathrm{nM})$

$\mathrm{NK} 3 \mathrm{IC}_{50}(\mathrm{nM})$

Reference

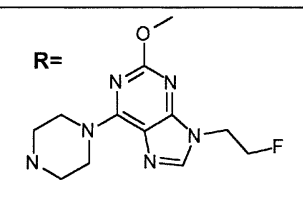

3,5 di-Me

0.45

9

25

[60]<smiles>CC(=O)N1CC2(CCNCC2)c2ccccc21</smiles>

3,4,5 tri-OMe

0.2

1.5

N.A.

[60]
$\mathbf{R}=$

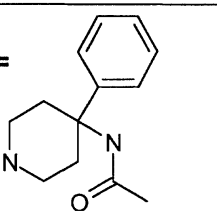

2 SR48968

$\mathrm{H}$

593

0.44

208

[37]<smiles>[R]CCC1(c2ccccc2)CCN(C(=O)c2ccccc2[Y])CC1</smiles><smiles>[R]CC1(c2ccccc2)CCNCC1</smiles><smiles>[R]CC1(c2ccccc2)CCNCC1</smiles>

$\mathrm{X}$

$\mathrm{Y}$

\section{3,4,5 tri-OMe}

3-Cl

10.7

190

N.A.

[61]

$\mathrm{H}$
$3,4-\mathrm{Cl}$
161
2.25
N.A.
$[37]$

3,4,5 tri-OMe

3,4-Cl

3.11

8.40

21.0

[37]

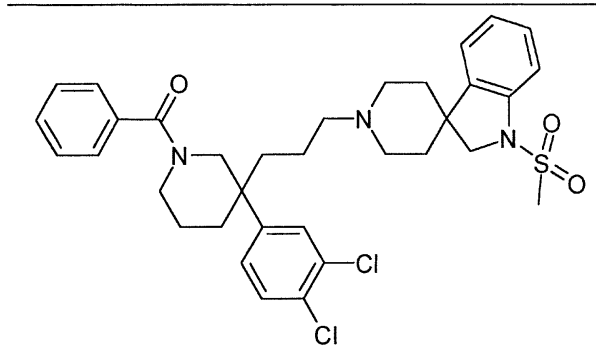

36

NK1 IC ${ }_{50} 497 \mathrm{nM}$

NK2 IC $_{50} 177 \mathrm{nM}$

NK3 IC I0 $_{50} 1.2 \mathrm{nM}$

Reference [37]<smiles>CN(Cc1ccccc1)C(=O)C(CCCN1CCC2(CC1)CN(S(C)(=O)=O)c1ccccc12)c1ccc(Cl)c(Cl)c1</smiles>

37

NK1 IC I0 $_{50} 100-500 \mathrm{nM}$

NK2 IC $_{50} 30 \mathrm{nM}$

NK3 IC $_{50} 0.6 \mathrm{nM}$

Reference [38]

N.A.: Not available. 

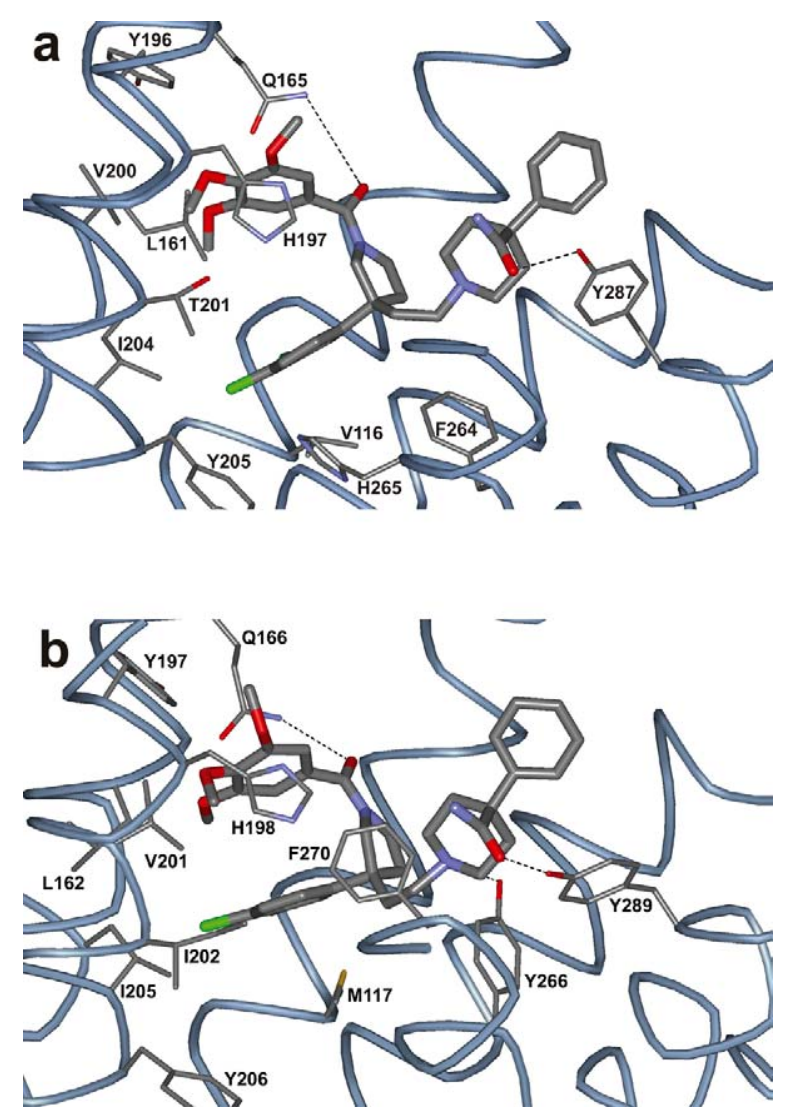

Figure 14. Compound 16 docked into the NK1R model (top) and NK2R model (bottom). Loops and the last three residues of helix 6 have been removed for clarity. Only sidechains identified by site-directed mutagenesis to be important for antagonist binding as well as residue Y287 in the NK1R are displayed.

lent residue in the NK3R is Glu218. When compound 2 is docked into the NK3R model a hydrogen bond between pharmacophore element E and Glu218 is observed. This interaction is not found for compound 37 . Instead pharmacophore element $\mathrm{E}$ of $\mathbf{3 7}$ can form a hydrogen bond to Tyr256. However, while the binding sites of NK1R and NK2R have been extensively explored by site directed mutagenesis, this is not the case for NK3R.

\section{Conclusions}

Three pharmacophore models (Models 1-3) for NK antagonists have been developed by use of a new procedure for treatment of hydrogen bonds during superimposition. The method results in more realistic RMS values than if hydrogen bonds in the strict direction of lone pairs were required and more pharmacophore elements can be incorporated in the pharmacophore models. Model 1 is identical to our previous model except that a hydrogen bond acceptor pharmacophore element has been added to the tail. The two novel models (Models 2 and 3) consist of three hydrophobic pharmacophore elements (A, B and C), a hydrogen bond donor element (D), and three hydrogen bond acceptor elements (E, F and G). The hydrogen bond donor-acceptor interactions are represented as vectors. In Model 2, the antagonists bind in an extended conformation with pharmacophore elements A and B in a parallel displaced conformation. In Model 3, pharmacophore elements B, C, D and G are in the same arrangement as in Model 1 and 2, but pharmacophore elements $\mathrm{A}$ and $\mathrm{B}$ are in an edge to ring face conformation.

Pharmacophore Model 2 and 3 models were evaluated against 21 structurally diverse, high affinity selective NK2, dual NK1/NK2 and NK1/NK2/NK3 antagonists. All compounds except five could be fitted to both models with a low conformational energy penalty and low RMS value. We believe that three of the remaining five compounds have another binding mode. The last two compounds could be fitted to Model 2 but not Model 3. Therefore we suggest that Model 2 represents the actual binding mode for the examined NK2 antagonists. This conclusion is supported by our receptor model study. Compounds fitted to pharmacophore Model 2 but not to Models 1 and 3 could be docked in the receptor models with only minor changes to the conformation of the head and tail fragments. The flexible linker connecting the fragments has another conformation in the docked conformations compared with pharmacophore Model 2. For each pharmacophore element except F, a specific interaction with the NK2R model was observed. This binding mode is compatible with published site directed mutagenesis data.

The new pharmacophore model (Model 2) represents a significant improvement in the description of the receptor binding properties of NK receptor antagonists compared to previously reported models. The larger number of pharmacophore elements in the new model should be an advantage in database searching for novel NK receptor ligands.

The NK1/NK2 subtype selectivity is determined by the substitution pattern of the pharmacophore elements $\mathrm{A}, \mathrm{B}, \mathrm{C}$ and $\mathrm{G}$ and not by differences in the bioactive conformations at the receptor subtypes. Therefore our pharmacophore models can be used for the design of both potent and selective NK1 and NK2 
antagonists. However, we believe that NK2/NK3 subtype selectivity is determined by either differences in the bioactive conformations at the receptor subtypes or that pharmacophore element $\mathrm{E}$ is interacting with different residues in the two receptor subtypes. These findings are also supported by our NK1R, NK2R and NK3R model study.

\section{Acknowledgements}

This work was financially supported by the Danish Academy of Technical Sciences, the Lundbeck Foundation and the NeuroScience PharmaBiotech Centre, which is gratefully acknowledged.

\section{References}

1. Regoli, D., Boudon, A. and Fauchere, J.L. Pharmacol. Rev., 46 (1994) 551.

2. Poulsen, A., Liljefors, T., Gundertofte, K. and Bjørnholm, B., J. Comput.-Aided Mol. Des., 16 (2002) 273.

3. Williams, D.E., Acta Crystallogr., A36 (1980) 715.

4. Greenfeder, S., Cheewatrakoolpong, B., Billah, M., Egan, R.W., Keene, E., Murgolo, N.J. and Anthes, J.C., Bioorg. Med. Chem., 7 (1999) 2867.

5. Blaney, F.E., Raveglia, L.F., Artico, M., Cavagnera, S., Dartois, C., Farina, C., Grugni, M., Gagliardi, S., Luttmann, M.A., Martinelli, M., Nadler, G.M., Parini, C., Petrillo, P., Sarau, H.M., Scheideler, M.A., Hay, D.W. and Giardina, G.A., J. Med. Chem., 44 (2001) 1675.

6. a. Palczewski, K., Kumasaka, T., Hori, T., Behnke, C.A., Motoshima, H., Fox, B.A., Le, T., Teller, D.C., Okada, T., Stenkamp, R.E., Yamamoto, M. and Miyano, M., Science, 289 (2000) 739.

b. Berman, H.M., Westbrook, J., Feng, Z., Gilliland, G., Bhat, T.N., Weissig, H., Shindyalov, I.N. and Bourne, P.E., Nucleic Acids Res., 28 (2000) 235. http://www.rcsb.org/pdb/

7. Elling, C.E., Thirstrup, K., Nielsen, S.M., Hjorth, S.A. and Schwartz, T.W., Fold. Des., 2 (1997) S76.

8. Elling, C.E. and Schwartz, T.W., EMBO J., 15 (1996) 6213.

9. Donnelly, D., Maudsley, S., Gent, J.P., Moser, R.N., Hurrell, C.R. and Findlay, J.B., Biochem. J., 339 ( Pt 1) (1999) 55.

10. Lundstrom, K., Hawcock, A.B., Vargas, A., Ward, P., Thomas, P. and Naylor, A., Eur. J. Pharmacol., 337 (1997) 73.

11. Cascieri, M.A., MacLeod, A.M., Underwood, D., Shiao, L.L., Ber, E., Sadowski, S., Yu, H., Merchant, K.J., Swain, C.J. and Strader, C.D., J. Biol. Chem., 269 (1994) 6587.

12. Fong, T.M., Yu, H., Cascieri, M.A., Underwood, D., Swain, C.J. and Strader, C.D., J. Biol. Chem., 269 (1994) 2728.

13. Fong, T.M., Yu, H., Cascieri, M.A., Underwood, D., Swain, C.J. and Strader, C.D., J. Biol. Chem., 269 (1994) 14957.

14. Ali, M.A., Bhogal, N., Fishwick, C.W. and Findlay, J.B., Bioorg. Med. Chem. Lett., 11 (2001) 819.

15. Giolitti, A., Cucchi, P., Renzetti, A.R., Rotondaro, L., Zappitelli, S. and Maggi, C.A., Neuropharmacology, 39 (2000) 1422 .
16. Henderson, R., Baldwin, J.M., Ceska, T.A., Zemlin, F., Beckmann, E. and Downing, K.H., J. Mol. Biol., 213 (1990) 899.

17. Baldwin, J.M., Schertler, G.F. and Unger, V.M., J. Mol. Biol., 272 (1997) 144.

18. Unger, V.M., Hargrave, P.A., Baldwin, J.M. and Schertler, G.F., Nature, 389 (1997) 203.

19. Macromodel 7.1. Schrödinger Inc., Portland, OR.

20. Hasel, T.F., Hendrickson, T.F. and Still, W.C., Tetrahedron Comput. Methods, 1 (1988) 103.

21. Still, W.C., Tempczyk, A., Hawley, R.C. and Hendrickson, T., J. Am. Chem. Soc., 112 (1990) 6127.

22. Boström, J., Norrby, P.-O. and Liljefors, T., J. Comput.-Aided Mol. Des., 12 (1998) 383.

23. Jaguar 4.1. Schrödinger Inc., Portland, OR.

24. Horn, F., Weare, J., Beukers, M.W., Hörsch, S., Bairoch, A., Chen, W., Edvardsen, Ø., Campagne, F. and Vriend, G., Nucleic Acids Res., 26 (1998) 275.

25. Pogozheva, I.D., College of Pharmacy, University of Michigan, Ann Arbor, MI, 2002.

26. Pogozheva, I.D., Lomize, A.L. and Mosberg, H.I., Biophys. J., 72 (1997) 1963.

27. Guntert, P., Braun, W. and Wüthrich, K., J. Mol. Biol., 217 (1991) 517.

28. Huang, R.R., Vicario, P.P., Strader, C.D. and Fong, T.M., Biochemistry, 34 (1995) 10048.

29. CHARMm. Accelrys Inc., San Diego, CA.

30. Sjöberg, P. In Van de Waterbeemd, H., Testa, B. and Folkers, G., (Eds.), Computer-Assisted Lead Finding and Optimization. Verlag Helvetica Chimica Acta, Basel, Switzerland, 1997 , p. 83.

31. Lommerse, J.P.M., Price, S.L. and Taylor, R., J. Comput. Chem., 18 (1997) 757.

32. Edmonds-Alt, X., Proietto, V., Broeck, D.V., Vilain, P., Advenier, C., Neliat, G., Fur, G.L. and Brelière, J.-C., Bioorg. Med. Chem. Lett., 3 (1993) 925.

33. Kubota, H., Kakefuda, A., Okamoto, Y., Fujii, M., Yamamoto, O., Yamagiwa, Y., Orita, M., Ikeda, K., Takeuchi, M., Shibanuma, T. and Isomura, Y., Chem. Pharm. Bull. (Tokyo), 46 (1998) 1538.

34. Burkholder, T.P., Kudlacz, E.M., Maynard, G.D., Liu, X.G., Le, T.-B., Webster, M.E., Horgan, S.W., Wenstrup, D.L., Freund, D.W., Boyer, F., Bratton, L., Gross, R.S., Knippenberg, R.W., Logan, D.E., Jones, B.K. and Chen, T.-M., Bioorg. Med. Chem. Lett., 7 (1997) 2531.

35. Shih, N.Y., Albanese, M., Anthes, J.C., Carruthers, N.I., Grice, C.A., Lin, L., Mangiaracina, P., Reichard, G.A., Schwerdt, J., Seidl, V., Wong, S.C. and Piwinski, J.J., Bioorg. Med. Chem. Lett., 12 (2002) 141.

36. Burkholder, T P., Kudlacz, E.M., Le, T.-B., Knippenberg, R.W., Shatzer, S.A., Maynard, G.D., Webster, M.E. and Horgan, S.W., Bioorg. Med. Chem. Lett., 6 (1996) 951.

37. Giardina, G.A.M., Raveglia, L.F. and Grugni, M., Drugs Future, 22 (1997) 1235.

38. Shah, S.K., Patent US5434158, 1995.

39. Kubota, H., Kakefuda, A., Nagaoka, H., Yamamoto, O., Ikeda, K., Takeuchi, M., Shibanuma, T. and Isomura, Y., Chem. Pharm. Bull. (Tokyo), 46 (1998) 242.

40. Burkholder, T.P., Kudlacz, E.M., Le, T.-B. and Maynard, G.D., Patent US5824690, 1998.

41. Giardina, G.A.M., Grugni, M., Graziani, D. and Raveglia, L.F., Patent WO-09852942, 1998.

42. Kubota, H., Fujii, M., Ikeda, K., Takeuchi, M., Shibanuma, T. and Isomura, Y., Chem. Pharm. Bull. (Tokyo), 46 (1998) 351. 
43. Mackenzie, A.R., Marchington, A.P., Middelton, D.S. and Meadows, S.D., Patent WO9719942, 1997.

44. Miller, S.C., Jacobs, R.T. and Shenvi, A.B., Patent EP-739891, 1996.

45. Nishi, T., Fukazawa, T., Ishibashi, K., Nakajima, K., Sugioka, Y., Iio, Y., Kurata, H., Itoh, K., Mukaiyama, O., Satoh, Y. and Yamaguchi, T., Bioorg. Med. Chem. Lett., 9 (1999) 875.

46. Shankar, B.B., Patent WO-09818785, 1998.

47. Selway, C.N. and Terrett, N.K., Bioorg. Med. Chem., 4 (1996) 645.

48. McCormick, K.D. and Lupo, A.T., Patent WO-09639383, 1996.

49. Shankar, B.B., Patent US5688960, 1997.

50. Smith, P.W., Cooper, A.W., Bell, R., Beresford, I.J., Gore, P.M., McElroy, A.B., Pritchard, J.M., Saez, V., Taylor, N.R. and Sheldrick, R.L., J. Med. Chem., 38 (1995) 3772.

51. Cooper, A.W.J., Adams, H.S., Bell, R., Gore, P.M., McElroy, A.B., Pritchard, J.M., Smith, P.W. and Ward, P., Bioorg. Med. Chem. Lett., 4 (1994) 1951.

52. Reichard, G., Aslain, R., Alaimo, C., Kirkup, M. and Lupo, A., Patent US5696267, 1997.
53. Mackenzie, A.R., Marchington, A.P., Meadows, S.D. and Middleton, D.S., Patent EP-791592, 1997.

54. Mackenzie, A.R., Marchington, A.P., Middelton, D.S. and Meadows, S.D., Patent WP9727185, 1997.

55. Burkholder, T.P., Maynard, G.D. and Kudlacz, E.M., Patent WO9827086, 1998

56. Oka, H., Lida, M., Sato, Y. and Honda, M., Patent WO9900388, 1999.

57. Harrison, T., Korsgaard, M.P., Swain, C.J., Cascieri, M.A., Sadowski, S. and Seabrook, G.R., Bioorg. Med. Chem. Lett., 8 (1998) 1343.

58. Monaghan, S.M., Alker, D. and Burns, C.J., Patent WO9857972, 1998

59. Shenvi, A.B., Jacobs, R.T., Miller, S.C., Macht, C.J. and Veale, C.A., Patent WO-09516682, 1995.

60. Gerspacher, M. and von Sprecher, A., Drugs Future, 24 (1999) 883.

61. Burkholder, T.P., Bioorg. Med. Chem. Lett., 7 (1997) 2531. 